Univerzitet u Novom Sadu, Filozofski fakultet -

Odsek za medijske studije, Novi Sad

DOI 10.5937/kultura1133306P

UDK 32.019.5:654.197(497.11)

316.772 .4

$351: 654.19(497.11)$

\title{
ODNOS JAVNOSTI
}

INEZAVISNOG

REGULATORNOG
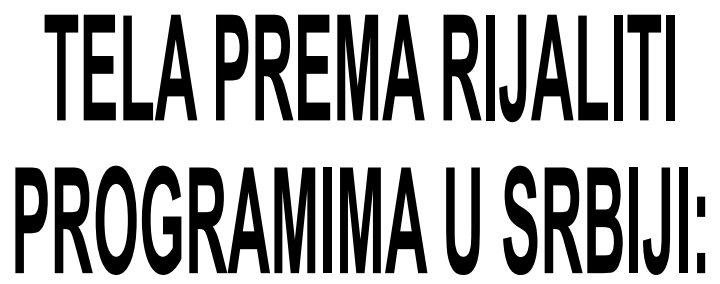

STUDUASLLCAAJADVOR

Sažetak: Među najpopularnijim programskim formatima na televizijama sa nacionalnom frekvencijom nalaze se ,rijaliti“ programi. Dok je najveći broj rijalitija pravljen po licenci, najgledanija komercijalna televizija u Srbiji, ,, Pink“, ponudila je publici u zemlji i regionu svoj rijaliti pod nazivom „Dvor“. Iako se u Srbiji rijaliti programi prikazuju od 2005, kontroverzne reakcije javnosti i medijskog regulatornog tela kulminirale su prilikom prikazivanja „Dvora“. Cilj ovog rada jeste da istraži zbog čega je „,Dvor“ izazvao najviše reakcije publike, štampanih medija, kao i medijskih stručnjaka i nezavisnog regulatornog tela, kada je u programu došlo do fizičkog nasilja među učesnicima i eksplicitnog govora mržnje. Opšta hipoteza jeste da je na veliku gledanost „Dvora" uticala zastupljenost tog programa u šemi matične TV kuće (više od 10 sati dnevno), kao i činjenica da su o dešavanjima i učesnicima $u$

rijalitiju vrlo opširno izveštavale dnevne novine i magazini.

Ključne reči: rijaliti program, „Dvor“, gledanost, govor mržnje, javnost, nezavisno regulatorno telo 


\section{DEJAN PRALICA}

\section{Uvodne napomene}

U savremenim društvima ne prođe dan, ${ }^{1}$ a da čovek ne bude bar nekoliko trenutaka u kontaktu sa televizijom, radiom, novinama ili internetom. U velikim razvijenim zemljama, u kojima većina građana nema mogućnosti da se susretne sa 99\% sugrađana, tj. sunarodnika, mediji imaju posebno značajnu ulogu jer su svojevrsni posrednici. „Na ličnom nivou oni obezbeđuju vezu sa širim društvenim grupama (...) i u određenoj meri osećaj povezanosti i solidarnosti“. ${ }^{2}$ Građani Srbije prvi su u svetu po broju sati provedenih uz TV ekran, zvanični su podaci iz istraživanja kompanije $A G B$ Nilsen (iz aprila 2010). Rezultati istraživanja ove agencije pokazali su da prosečan gledalac televizijskog programa u Srbiji provede tokom godine više od pet sati dnevno pred ekranom. U Srbiji se, tako, najradije gledaju domaće serije, rijaliti programi i sportski prenosi, a televizuju najviše prate stari, deca, nezaposleni i studenti. ${ }^{3} \mathrm{Na}$ taj način, građani Srbije postali su svetski rekorderi po broju sati gledanja i tako pretekli Amerikance, koji su do sada najviše bili uz televizijske ekrane. Kao što je navedeno $\mathrm{u}$ pomenutom istraživanju, među najpopularnijim programskim formatima na televizijama sa nacionalnom frekvencijom, nalaze se rijaliti programi. Dok je najveći broj rijalitija pravljen po licenci, najgledanija komercijalna televizija u Srbiji, Pink, ponudila je publici u zemlji i regionu svoj rijaliti pod nazivom $D v o r$. Iako se u Srbiji rijaliti programi prikazuju od 2005. (Veliki brat, Operacija trijumf, Survivor, Farma, Parovi, 48 sati svadba, Menjam ženu, Ja imam talenat, Radna akcija, Domaćine, oženi se, Paklena kuhinja, Vreme je za bebe, Gavrilovići, Maldivi, Vitezovi iz blata), kontroverzne reakcije javnosti i medijskih stručnjaka, kao i nezavisnog regulatornog tela kulminirale su prilikom prikazivanja Dvora.

\section{Cilj rada i hipoteze}

Cilj ovog rada jeste da istraži zbog čega je Dvor izazvao najviše reakcije publike (od odobravanja do osporavanja), štampanih medija (detaljni dnevni bilteni izveštavanja šta se dešavalo unutar rijalitija), kao i medijskih stručnjaka i nezavisnog regulatornog tela kada je u programu došlo do fizičkog nasilja među učesnicima i eksplicitnog govora mržnje. Opšta hipoteza jeste da je na na veliku gledanost Dvora uticala zastupljenost

1 Ovaj rad predstavljen je na Međunarodnom interdisciplinarnom simpozijumu Filozofija medija (Cres, Hrvatska 16-18. 9. 2011).

2 Pralica D., Big brother te gleda, Link br. 35, Novi Sad 2005, str. 5., prema Herman E.S. i Mekčesni R. V., Globalni mediji, Beograd 2004, str. 7-9.

3 Podaci dostupni na http://www.krunet.net/vesti\%20sr.htm (posećeno 1. 9. 2011). 


\section{DEJAN PRALICA}

tog programa u šemi matične TV kuće (više od 10 sati dnevno), kao i činjenica da su o dešavanjima i učesnicima u rijalitiju vrlo opširno izveštavale dnevne novine i magazini. Prva posebna hipoteza jeste da je Dvor izazvao veoma veliko interesovanje publike, ali i većine medija, jer su u njemu učestovale poznate ličnosti. Druga posebna hipoteza jeste da reakcije i odluke nezavisnog regulatornog tela - Republičke radiodifuzne agencije, nakon incidenata u rijalitiju, nisu u dovoljnoj meri ispunile očekivanja stručne javnosti.

\section{Metodologija}

Metode koje su korištene u ovom istraživanju su: kvantitativno-kvalitativna diskursna analiza medijskog sadržaja, dekriptivni metod, kao transkripcija. Analiza sadržaja nastala je kao rezultat praktičnih i teorijskih potreba da se pojedinačnim oblicima društvene komunikacije dobiju objektivniji i precizniji podaci. ${ }^{4}$ Analiza diskursa, kao interdisciplinarno područje, kritički preispituje društvo i kulturu u kojoj sagovornici (u ovom istraživanju učesnici rijalitija, ali i publika i stručnjaci) razmenjuju poruke (razgovorne sekvence u rijalitiju). Ono što je jedinstveno za metodu jeste da ,analiza jedinica većih od rečenice, u konkretnoj upotrebi u kontekstu i situaciji, bolje objašnjava ljudsku komunikaciju i ponašanje“"5. Medijski diskurs jeste širok pojam koji može da se odnosi na sveukupnu stvarnost, predstavljenu kroz štampane i elektronske medije ${ }^{6}$, u kojima se govori o ekscesima na Dvoru. Deskriptivnom metodom istražujemo situacije koje zahtevaju primenu tehnika posmatranja kao glavnog načina prikupljanja podataka. ${ }^{7} \mathrm{U}$ ovom istraživanju, opisuju se modeli komuniciranja učesnika rijalitija, kao i reakcije medija i stručne javnosti na ponašanje učesnika rijalitija. Transkripcija predstavlja prenošenje govornog materijala u pisanu formu, gde se podjednaka pažnja poklanja verbalnim i neverbalnim znakovima. Ona je deo istraživačkog metalingvističkog aparata na osnovu kojeg sačinjava analizu diskursa. ${ }^{8} \mathrm{U}$ ovom istraživanju transkribuju se segmetni rijalitija u kojima je

4 Prema Milić V., Sociološki metod, Beograd 1978, str. 571.

5 Savić S., Diskurs analiza, Novi Sad 1993, str. 25.

6 Prema Van Dijk T. A., The Study of Discourse. Discourse as Structure and Process-Discourse Studies: A Multidisciplinary Introduction Vol 1, London 1998, str. 2-3.

7 Afrić V., Karakteristike deskriptivnog ili normativnog pristupa, u: Baza znanja: Metode istraživanja u društvenim znanostima, projekat: Izgradnja i multiplikacija modela interdisciplinarnog kurikularnog pristupa suvremene multimedijalne nastave - Edukacija mladih sveučilišnih nastavnika o inovativnim metodama sveučilišne nastave. Zagreb 2003, 1.9.2011., http:// infoz.ffzg.hr/Afric/vjekobz/CITABAZU.asp?kljuc=2

8 Prema Savić S., Diskurs analiza, Novi Sad 1993, str. 54-61, 159. 


\section{DEJAN PRALICA}

došlo do ekscesnih situacija - govora mržnje i fizičkog obračuna među učesnicima.

\section{Rijaliti format}

Poslednjih godina, velika popularnost televizijskih emisija/programa čija su tematika scene iz realnog života učesnika koji svoj život, u određenom periodu, 24 sata žive pred kamerama, donela je u Srbiju 2006. i novi medijski format - rijaliti šou (eng. reality show). ${ }^{9}$ Srpski jezik i medijska scena, čini se, tada nisu imali spreman prevod za ovaj novi format tako da je do danas on postao odomaćen, a rijaliti programi samo su se umnožavali. Neki lingvisti predlagali su prevođenje ovog termina na srpski jezik. Tako se u Dnevnikovom TV magazinu u rubrici Jezikomanija, autorka Nataša Mirković zapitala „kako bi se mogla prevesti sintagma reality show? „Moglo bi se reći program o stvarnom životu, šou o običnim ljudima, život uživo, šou iz stvarnosti, prirodni šou program, pravi šou, realni šou..."10 Za ovaj medijski format navodi se da je „vrsta televizijskog programa u kojem se prikazuju neinscenirane, dramatične ili smešne situacije stvarnih događaja čiji su akteri stvarni ljudi, a ne profesionalni glumci”, koji se takmiče za nagradu, uz učešće publike koja utiče na one što ostaju i one što ispadaju iz igre. ${ }^{11}$ Rijaliti televizijski programi „gledaocima prikazuju emocije, otkrića, tračeve i druge forme bliskog razgovora spontano započetog" ${ }^{\prime 2}$. „Popularno nazvana televizija sa činjenicama (factual TV), rijaliti je smešten negde na granici između informacije i zabave, dokumentarca i drame."13 Osnova svakog rijaliti programa, između ostalog, mogla bi biti zajednička - ,zaključati ljude u kuću, snimati svaki njihov pokret danonoćno"14, tj. oduzeti ličnu slobodu takmičarima u zamenu za novčanu nagradu, bogatstvo $i$ popularnost u javnosti.

Ipak, o popularnosti rijalitija u Srbiji, od pojave Velikog brata na TV B92 (2006), do poslednjeg Maldiva na TV Košava i Vitezova iz blata na TV Pink (2011), mogli smo gledati na desetine

9 Iako se rijaliti šou u Srbiji pojavio 2001. na TV Košava, pod nazivom Cirkus voajer, vrlo skromne produkcije i bez veće medijske pažnje i popularnosti, prvi pravi licencirani program jeste Veliki brat.

10 Mirković N., Prirodni šou program, Dnevnikov TV magazin, Novi Sad, 1016. 9. 2011., str. 1.

11 Prema Namkosse B. B., Rialiti televizijski format sa posebnim osvrtom na emisiju Veliki brat, $C M$ br. 10, Novi Sad - Beograd 2009, str. 51.

12 Lorenzo-Dus N., Television Discourse: Analysing Language in the Media, New York 2009, str. 62.

13 Holmes S. i Deborah J., Understanding Reality TV, New York 2004, pp.2.

14 Hill A., Reality TV, Audiences and Popular Factual Television, LondonNew York 2005, str. 1-13. 


\section{DEJAN PRALICA}

programa koji su bili zasnovani na istom, ili vrlo sličnom konceptu, koji su bili vrlo popularni i donosili velike zarade televizijskim kućama što su ih emitovale. Ovakav tip programa u početku, tj. nekoliko sezona, donosi veliku gledanost jer predstavlja nešto novo na medijskoj sceni određene zemlje, ali takav format finansijski je isplativ samo ako „na duže staze opravdava troškove i privlači gledaoce na što duže gledanje"15.

Iako širom sveta ovaj medijski format polako postaje prevaziđen, u Srbiji je rijaliti vrlo popularan, a „većina ovakvih programa promoviše nepostojanje moralnih vrednosti i prostakluk, kao i zadovoljavanje najnižih pobuda kod gledalaca“"16.

\section{Analiza i rezultati}

Jedan od rijalitija koji je izazvao najviše reakcija publike, stručne javnosti, ali i nezavisnog regulatornog tela u Srbiji jeste Dvor. To je bio još jedan u nizu sličnih programa. On je polovinom januara 2011. počeo da se emituje na komercijalnoj TV Pink u Srbiji i u svim zemljama bivše Jugoslavije. Vlasnik tog medija, Željko Mitrović, neposredno pred početak emitovanja, izjavio je kako je Dvor ,autentični format (TV Pinka), nigde u svetu nije emitovan i biće potpuno osveženje, a pored takmičara iz Srbije učestvovaće i VIP ličnosti iz drugih eks-jugoslovenskih republika" ${ }^{\text {"17 }}$. Koncepcija ovog šoua je takva da se svake nedelje tokom trajanja (60 dana) biraju kralj, kraljica, nadzornik i dvorska luda, dok su ostali takmičari seljani i oni ne žive na dvoru, već u odvojenoj, zajedničkoj kući i obavljaju određene zadatke. ${ }^{18}$

Početak Dvora, prema istraživanjima agencije $A G B$ Nilsen, pratilo je oko $37 \%$ auditorijuma koji je tog trenutka bio uz televizijske ekrane, što je ovaj rijaliti postavilo na sedmo mesto po gledanosti u januaru 2011. ${ }^{19}$ Do mnogo većeg interesovanja javnosti za ovaj šou došlo je nakon incidenata koji su usledili.

$\mathrm{Na}$ veliku gledanost rijalitija Dvor najviše uticaja imala su dva incidenta koja su se dogodila u kratkom intervalu od nekoliko nedelja. Prvi incident odigrao se 17. 2. 2011, kada je došlo do

15 Prema Bignell J., Big Brother - Reality Television in the Twenty-First Century, Basingstoke 2005, str. 43.

16 Bojić D., Fenomen Farme u Srbiji i svetu, seminarski rad, Filozofski fakultet, Univerzitet u Novom Sadu, Novi Sad 2011, str. 4.

17 Dostupno na: http://www.dvor-srbija.com/dvor-srbija/dvor-reality-show-ujanuaru-na-pink-tv.html (posećeno 1. 9. 2011).

18 Takmičar koji sakupi najveći broj zlatnika, na kraju rijalitija, osvaja nagradu od 10.000 evra, tako da Dvor ima dva pobednika - jednog koga izglasa publika SMS porukama, i drugog, koji sakupi najviše zlatnika!

19 Popularnije od Dvora prilikom istraživanja u januaru 2011. bile su domaće serije. Dostupno na: http://www.novosti.rs/vesti/spektakl.147.html:320683Rijaliti-dlaku-menja (posećeno 1. 10. 2011). 


\section{DEJAN PRALICA}

fizičkog obračuna između dvojice ukućana. Kako bi se realnije sagledala situacija u kojoj je došlo do obračuna, metodom transkripcije, ${ }^{20}$ predstavljene su sporne scene koje su za posledicu imale mnogobrojne reakcije javnosti i medijskih stručnjaka, ali i političara.

Scena Fizički obračun odigrava se u glavnoj sali dvora 17. 2. 2011.21

Miloš Bojanić (sedi u kraljevskom tronu, sve vreme gestikulira rukama): ovde su postojali ljudi sa kojima ja --- iz prethodnog perioda nisam bio u dobrim odnosima - odnosno čovjek prema kojem - koji se poneo drugacije // i ja sam dokazao celoj naciji da postoji --<da postoji dobra volja $>$ prema nekom ko je normalan da ja ispravim svoje stavove i taj s druge strane- kako sam ja mogao da menjam bilo šta - è vanesi se obraćam - a i svima vama - prema čoveku koji je izgovorio što to što nijedan $<$ normalan $>$ mozak ne može da kaže $-==$

Samo da vam $==/ /$

Neko od ukućana, neidentifikovano ko: $==$ $<$ ko je taj $>==$

Miloš: samo da vam kažem +++fece+++ ko vam je idejni vođa - vi koji podležete - bio sam prisutan i kamere su snimile kada je gospođu bebi dol ispred mene nagovarao da ne radi - da ne komunicira sa mnom - jer neće s njom progovoriti - jer on je autoritet $<$ a reći ću vam prvo šta sam pročitao u novinama kada sam izašao sa farme $>$ a to je izjavu njene - njegove sestre +++ po ocu +++ koja je napisala istinu o njegovom zlostavljanju sestre +++ po ocu $+++<$ eto koga vi sledite i eto $\mathrm{s}$ kim vi imate $>-\mathrm{s}$ kim vi - koga vi imate $-<$ to je istina ja imam novine-ja ne izmišljam - ja ne izmišljam $>$ ja sam tebe izabrao ko zna kolko puta//Firči (uzima u ruke plastičnu flašu pića, ustaje, penje se na sto i prosipa piće po milošu): <još jednom mi spomeni familiju>Miloš (briše se): pazi --- mene nije sramota da budem poliven -al da sam zlostao - zlostavljao sestru seksualno njega ni to nije sramota

20 Znaci za transkripciju dati su u prilogu na kraju rada. Postupak transkripcije teksta ne mora da podrazumeva poštovanje pravopisa, pravilnu distribuciju velikog i malog slova.

$21 \mathrm{http}: / /$ www.youtube.com/watch?v=JrE9g_O_xXA (posećeno 29. 8. 2011). 
Boki (dobacuje): <miloše - stvarno je ovo katastrofa $>$

Firči: (opet se penje na sto i poliva Miloša sokom iz flaše ponovo)

Miloš: Da da da ja sam to čitao

Firči: (pogađa Miloša flašom u oko)

Bebi Dol: $<$ krunski - on ima modricu - ovo je fizički napad $>+++<$ krunski - dođite zato što ima krvavo oko miloš - raskrvario mu je oko>

Drugi incident odigrao se 26. 2. 2011. kada je došlo do eksplicitnog govora mržnje učesnika rijalitija prema pripadnicima jevrejske nacionalnosti.

Scena Govor mržnje odigrava se u glavnoj sali Dvora 26.2.2011. ${ }^{22}$

Mika (sedi za stolom preko puta Miloša i Maje): ja ću tebe da tužim

Maja: <zašto ti imaš mene da tužiš >

Mika: zato što si antisemita -- rasista $=$

Maja: $==$ što ne volim Jevreje koji su stvorili Ameriku

Mika: tako je -- ne voliš -- antisemita si //

Miloš: šta ti imaš s Jevrejima

Maja $<$ šta ti imaš mene da tužiš/. slobodno me tuži za to $>==$

Mika: $==\mathrm{i}$ zato što si direktno udarila na mene $\mathrm{i}$ moju familiju --i zato što si nacionalista a ja //

Maja: $==<$ jeste nacionalista sam i obožavam Srbi$\mathrm{ju}>$ nisam šovinista ali sam nacionalista -- ponosim se $\operatorname{tim}==$

Miloš: $==$ miko -- pa kako da volimo Jevreje koji su nas bombardovali koji su nam uranijum poslali i rakove $\mathrm{i}$ čuda $==$

Mika: samo vi pričajte snimaju sve kamere

Uzroci pojave fizičkog nasilja i govora mržnje na nacionalnim televizijama u Srbiji mogu svoje uporište imati u primitivizmu

$22 \mathrm{http}: / /$ www.youtube.com/watch? $\mathrm{v}=\mathrm{oMfREJ}$ fPKR $4 \&$ feature=related (posećeno 25. 8. 2011). 


\section{DEJAN PRALICA}

samih učesnika takvih programa. Jer, kako je zapazio Jost Smirs, „kamera sve snima, a gledalac se kao voajer nada da će se među njima (učesnicima) dogoditi nešto spektakularno: svađe, ljubav, seks, bilo šta." ${ }^{\text {23 }}$ Neodgovornost vlasnika i urednika medija takođe može biti jedan od uzroka neprimerenog ponašanja aktera. Vlasnik i portparolka TV Pinka, Željko Mitrović i Tatjana Vojtehovski, ne vide krivicu tog medija u ponašanju učesnika rijalitija. Mitrović je potvrdio da su fizički obračuni zabranjeni i napomenuo da ako do fizičkog obračuna dođe, to nije stvar za Republičku radiodifuznu agenciju, već za policiju. „Ništa što smo mi pripremili u okviru formata Dvor ne podstiče ljude na fizičko nasilje, niti na međusobne obračune i svađe", kaže Mitrović. ${ }^{24}$ Vojtehovska smatra da su rijaliti gledani, a da je situacija u njima slična kao i u Narodnoj skupštini Srbije. „Ne možemo zanemariti činjenicu da ove sadržaje gleda dva miliona ljudi i da se u srpskom parlamentu dešavaju slične epizode poput onih u rijaliti programima. Setimo se incidenta u kome je (poslanica) Gordana Pop Lazić cipelom gađala (potpredsednicu parlamenta) Gordanu Čomić i promašila. Srbija se danas deli na Firčijevu i Bojanićevu publiku. Strašno je ono što se dogodilo, ali sve to čini sastavni deo rijaliti šoua", ocenila je Tatjana Vojtehovski. ${ }^{25}$ Velika popularnost ovog tipa programa, zajedno sa komercijalizacijom medija i nepismenom ${ }^{26}$ publikom, još je jedan od uzroka problema. Nije nepoznanica da je „televizija od svog uvođenja četrdesetih godina prošlog veka (...) pa do sada ostala glavni potrošač i propagator spektakla.” Postala je ,dominantni medij za širenje popularnih live reality programa (...) u kojima se nalazi spektakl intime, međusobnog ponižavanja, preziranja"27. Stručna javnost ${ }^{28}$ je, gotovo jednoglasno, osudila ovaj format, ali i medije koji dopuštaju da se takvi programi nađu u njihovoj šemi.

Nedopustivo je to što TV Pink nije prekinula program istog trenutka kada su Maja Nikolić i Miloš Bojanić počeli da vređaju

23 Smirs J., Umetnost pod pritiskom - promocija kulturne raznolikosti u doba globalizacije, Novi Sad 2004, str. 198.

24 Dostupno na http://www.blic.rs/Zabava/Vesti/236494/RRA-blago-kaznilaPink-na-Dvoru-nastavili--sa-sukobima (posećeno 1. 10. 2011).

25 Dostupno na: http://www.politika.rs/rubrike/Drustvo/Rijaliti-programipecat-savremenog-drustva.lt.html (posećeno 1. 10. 2011).

26 Misli se na medijsku nepismenost.

27 Ćelebić J., Medijski spektakl - povlaštena mjesta medijske kulture, Odjek, Sarajevo 2008. Dostupno na http://www.odjek.ba/index.php?broj=16\&id=30 (posećeno 1.10.2011).

28 Dostupno na: http://www.nuns.rs/vesti/view.jsp?articleId=14380 ;http:// www.nuns.rs/vesti/view.jsp?articleId=14379; http://www.nuns.rs/vesti/view. jsp?articleId=14347 ; http://www.nuns.rs/vesti/view.jsp?articleId=14374 (poseæeno 1.10.2011). 


\section{DEJAN PRALICA}

Jevreje. Međutim, jevrejsku zajednicu ne interesuje ovo dvoje pevača. To dvoje ljudi koji su pokazali elementarno nepoznavanje događaja i istorije. Nas može da voli ili mrzi ko hoće. Ne sme da prođe nekažnjeno to što je TV Pink, koja ima nacionalnu frekvenciju, pred milionskim gledalištem emitovala govor $\mathrm{mr}$ žnje i omogućila izvršenje krivičnog dela. Ali, toj televiziji je očigledno mnogo važnija gledanost, nego širenje rasne, verske $i$ nacionalne mržnje. (predsednik Saveza jevrejskih opština Srbije Aleksandar Nećak)

U većini civilizovanih društava rijaliti programi su ukinuti, jer je intima učesnika bila ogoljena do granice estetskih $i$ etičkih načela, a mi smo oberučke prigrlili ono što svet odbacuje. Nažalost, rijaliti programi su postali deo svakodnevice velikog broja ljudi, a meni kao sociologu nije jasno zašto se u takve programe ubacuju ljudi koji su problematični sa stanovišta razuma $i$ normalnog ponašanja. (sociolog Ratko Božović)

Rijaliti programi predstavljaju neku vrstu socijalnog eksperimenta, a eksperiment sa ljudima nikada se ne može u potpunosti kontrolisati. (sociolog Vladimir Vuletić)

Glavni problem je što takve emisije nemaju scenario ili im daju zadatke koji su bledi pokušaji scenarija $i$ koji gledaocima uglavnom nisu zanimljivi, pa promene kanal. Zato ubacuju ljude koji imaju neke konflikte odranije ili se ne podnose jer znaju da će to dati određenu dinamiku.

(psihoterapeut Zoran Milivojević)

Dobar deo odgovornosti je na RRA jer oni i ne reaguju na pozive $i$ kritike vezane za takve programe, a iznad njih nema vlasti za tu oblast. (književnik Filip David)

Tužilaštvo je reagovalo jer postoji osnovana sumnja da su određeni učesnici rijalitija izvršili krivično delo izazivanja nacionalne, rasne i verske mržnje i netrpeljivosti (portparol državnog tužioca Tomo Zorić)

Fizički obračun u rijalitiju bio je povod da se sazove sednica Saveta Republičke radiodifuzne agencije (RRA) kako bi se pokušala osujetiti popularizacija nasilja u medijima. Savet RRA naložio je televizijama Pink i Hepi da iz svojih rijaliti programa uklone svaki sadržaj koji ,teško ugrožava fizički, mentalni i moralni razvoj maloletnika i narušava dostojanstvo ličnosti”. Iz prilično uopštenog saopštenja koje je Savet izdao nakon sednice, kojoj su prisustvovali i predstavnici dve pomenute televizije na kojima se emituju kontroverzni programi, proizlazi da 


\section{DEJAN PRALICA}

će Pink nakon niza scena brutalnog nasilja u Dvoru proći sa opomenom i blagim kaznama. ${ }^{29}$

Prethodno je pokazano kako na pragmatičkom nivou izgleda fenomen rijalitija i kakvi su uzroci i posledice popularnosti ovog formata u Srbiji danas. S druge strane, i teoretičari medija, kao i filozofi, saglasni su u tome da je ovaj format, upravo zbog svoje kontroverznosti, zanimljiv kao fenomen savremenog doba, ali koji ima svoje uporište još sredinom XX veka, na šta je ukazao i Gi Debor, pominjući spektakl kao i „vizuelnu obmanu koju stvaraju mediji“, ali i kao „pogled na svet koji se materijalizovao $^{\text {"30 }}$. I zaista, mediji se danas potvrđuju na tržištu koje opet iznova utiče na njihov sadržaj. „Eksplicitna kritika komercijalnih reality televizija (...), prerasla je, na ovaj način, u imanentnu kritiku sveta masovnih medija i globalne zabave, koja unutar samog filmskog medija, korišćenog na autorski (subjektivni) način, progovara o medijskoj ontologiji kao o sferi intencionalnih konstrukcija i tehnološkim sredstvima proizvedenih opscena, $u$ pokušaju legitimizacije, pa i same 'ontologizacije' kontroverzne sfere estetskog privida. " ${ }^{31}$ Činjenica je da se u modernom društvu XXI veka meri isključivo čitanost (tiraž), a ne pismenost, gledanost televizijskih programa, a ne osvešćenost publike. U ovom smislu, kvantitet je svakako odneo prevagu nad kvalitetom. Zbog toga ni ne čudi što može da se tvrdi da je „za naše doba karakterističan medijski rat između literarnog i audiovizuelnog, sa tendencijom da knjiga, a sa njom i autonomija ličnosti budu istisnuti od strane televizije ${ }^{\text {“32. }}$. Moglo bi se reći da se danas raznim piplmetrima u stvari meri medijska poslušnost, dok obrasce ponašanja koje vidimo na televiziji vrlo lako usvajamo i kasnije primenjujemo u realnosti. Na taj način, novi mediji utiču i ,na one delove naših života kada tim medijima nismo izloženi““33. Da li interesovanje za tuđe živote može da bude u korelaciji sa tim da je sve u redu sa našim životom?

\section{Zaključne napomene}

Opšta hipoteza da je na veliku gledanost Dvora uticala zastupljenost tog programa u šemi matične TV kuće (više od 10 sati dnevno), kao i činjenica da su o dešavanjima i učesnicima u rijalitiju vrlo opširno izveštavale dnevne novine i magazini,

29 Dostupno na http://www.blic.rs/Zabava/Vesti/236494/RRA-blago-kaznilaPink-na-Dvoru-nastavili--sa-sukobima (posećeno 1.10.2011).

30 Debor G., Društvo spektakla, Beograd 2003, str. 8.

31 Vuksanović D., Filozofija medija - ontologija, estetika, kritika, Beograd 2007, str. 15.

32 Prole D., Medijska konstrukcija stranog-Makluanova kritika Gutenbergovog doba i nada u audiovizuelne medije, Arhe br. 11, Novi Sad 2009, str. 152

33 Alić S., McLuhan - Najava filozofije medija, Zagreb 2010, str. 245. 


\section{DEJAN PRALICA}

delimično je potvrđena, s obzirom na to da Dvor ipak nije zabeležio gledanost kao prethodni šou Farma, iako se to očekivalo. Prva posebna hipoteza da je Dvor izazvao veoma veliko interesovanje publike, ali i većine medija, jer su u njemu učestovale poznate ličnosti, nije potvrđena. Razlog je taj što se ponuda ovog formata na nacionalnim televizijama izvesno vreme svela na poznate ličnosti, ${ }^{34}$ takozvane $V I P$, što je uticalo na delimičan pad gledanosti, s obzirom na to da su često jedne te iste VIP ličnosti učestvovale u nekoliko rijalitija zaredom. Druga posebna hipoteza da reakcije i odluke nezavisnog regulatornog tela - Republičke radiodifuzne agencije, nakon incidenata u rijalitiju, nisu u dovoljnoj meri ispunila očekivanja stručne javnosti potvrđena je, pošto je stručna javnost, ali i institucije, daleko oštrije reagovala od RRA i ukazala na nedopustivost politički nekorektnog ponašanja i promovisanja fizičkog nasilja i govora mržnje.

Veoma je lako manipulisati publikom koja je na nižem obrazovnom nivou, pa su otuda i uspešniji primitivni medijski sadržaji što se nude $u$ trenutku svetske ekonomske krize, kada je većina ljudi zatvorena kod kuće i kada ima puno slobodnog vremena, koje, očigledno, troši gledajući televizijske programe. Ovakva situacija može se delimično promeniti i kod generacija koje dolaze jedino uvođenjem predmeta medijska pismenost u osnovno i srednje obrazovanje. Potrebno je da (prosečan) gledalac u Srbiji počne kritički da prati televizijske sadržaje i postane u stanju da odgovori na pitanje da li je interesovanje za tuđe živote $u$ funkciji potvrđivanja da je sve u redu sa njegovim životom. Jer ćemo se u suprotnom uklopiti u konstataciju Zigfreda Krakauera da „nekritičko konzumiranje medija označava dobrovoljnu suspenziju vlastite humanosti i duhovnosti““35. Primitivno ponašanje učesnika u rijaliti programima ne sme da podstakne publiku da se i ona tako ponaša u realnom svetu, a samo medijski pismena publika može da shvati implicitnu poruku ovih medijskih formata - da se zbog novca neretko pristaje i na najbizarnija poniženja, što je poražavajuće za čoveka.

\section{Dodatak:}

\section{Znaci za transkripciju}

-- kratka pauza

--- duga pauza

---- veoma duga pauza

34 VIP Veliki brat, VIP Farma.

35 Kracauer S., Die Photographie, Das Oranament der Masse, Frankfurt 1977, str. 33 . 


\section{DEJAN PRALICA}

$<>$ tekst između ovih znakova posebno naglašen

+++ ne čuje se ili ne razume tekst

$=====$ preklapanje, govorenje uglas

è neartikulisan glas

Y uzdah

aa produženo trajanje vokala

// nezavršen iskaz

\section{LITERATURA:}

Alić S., McLuhan - Najava filozofije medija. Zagreb 2010.

Afrić V., Karakteristike deskriptivnog ili normativnog pristupa, Baza znanja: Metode istraživanja u društvenim znanostima, projekat: Izgradnja i multiplikacija modela interdisciplinarnog kurikularnog pristupa suvremene multimedijalne nastave - Edukacija mladih sveučilišnih nastavnika o inovativnim metodama sveučilišne nastave, Zagreb 2003.Dostupno na: http://infoz.ffzg.hr/Afric/vjekobz/CITABAZU. asp?kljuc $=2$ (posećeno 13.5.2011)

Bignell J., Big Brother - Reality Television in the Twenty-First Centu$r y$, Basingstoke 2005.

Bojić D., Fenomen Farme u Srbiji i svetu - seminarski rad iz predmeta Kritička analiza medijskog diskursa na master studijama Komunikologija, Filozofski fakultet, Univerzitet u Novom Sadu, Novi Sad 2010.

Čelebić J., Medijski spektakl - povlaštena mjesta medijske kulture. Odjek - revija za umjetnost, nauku i društvena pitanja, Sarajevo 2008. Dostupno na: http://www.odjek.ba/index.php?broj=16\&id=30 (posećeno 1. 10. 2011).

Deborg G., Društvo spektakla, Beograd 2003. Dostupno na: http:// www.crsn.com/debord/Drustvo_spektakla_Gi_Debor.pdf

Herman E. S. i Mekčesni R. V., Globalni mediji, Beograd 2004.

Hill A., Reality TV, Audiences and Popular Factual Television, London, New York 2005.

Holmes S. i Deborah J., Understanding Reality TV, New York 2004.

Kracauer S., Die Photographie. Das Ornament der Masse, Frankfurt 1977.

Lorenzo-Dus N., Television Discourse: Analysing Language in the Media, New York 2009.

Milić V., Sociološki metod, Beograd 1978.

Mirković N., Prirodni šou program. Jezikomanija. Dnevnikov TV magazin (od 10. do 16. 04. 2011), Novi Sad 2001, str. 1. 


\section{DEJAN PRALICA}

Namkosse B. B., Rialiti televizijski format sa posebnim osvrtom na emisiju Veliki brat, CM - časopis za upravljanje komuniciranjem, god. IV, br. 10, Novi Sad - Beograd 2009, str. 49-70.

Pralica D., Big brother te gleda, Link-časopis za profesionalce $u$ medijima, god. IV, br. 35, Novi Sad 2005, str. 5.

Prole D., Medijska konstrukcija stranog - Makluanua kritika Gutenbergovog doba i nada u audiovizuelne medije, Arhe - časopis za filozofiju, godina VI, br. 11, Novi Sad 2009, str. 151-167

Savić S., Diskurs analiza, Novi Sad 1993.

Smirs J., Umetnost pod pritiskom - promocija kulturne raznolikosti u doba globalizacije, Novi Sad 2004.

Van Dijk T. A., The Study of Discourse. Discourse as Structure and Process - Discourse Studies: A Multidisciplinary Introduction. Vol. 1, London 1998, str. 1-34.

Vuksanović D., Filozofija medija - ontologija, estetika, kritika. Beograd 2007.

\section{VEB-SAJTOVI:}

http://www.krunet.net/vesti\%20sr.htm (posećeno 1. 9. 2011).

http://www.dvor-srbija.com/dvor-srbija/dvor-reality-show-u-januaruna-pink-tv.html (posećeno 1. 9. 2011).

http://www.novosti.rs/vesti/spektakl.147.html:320683-Rijaliti-dlakumenja (posećeno 1. 10. 2011).

http://www.youtube.com/watch?v=JrE9g_O_xXA (posećeno 29. 8. 2011).

http://www.youtube.com/watch? $\mathrm{v}=\mathrm{oMfREJfPKR} 4 \&$ feature=related (posećeno 25. 8. 2011).

http://www.blic.rs/Zabava/Vesti/236494/RRA-blago-kaznila-Pink-naDvoru-nastavili--sa-sukobima (posećeno 1. 10. 2011).

http://www.politika.rs/rubrike/Drustvo/Rijaliti-programi-pecatsavremenog-drustva.lt.html (posećeno 1. 10. 2011).

http://www.nuns.rs/vesti/view.jsp?articleId=14380 (posećeno 1. 10. 2011).

http://www.nuns.rs/vesti/view.jsp?articleId=14379 (posećeno 1. 10. 2011).

http://www.nuns.rs/vesti/view.jsp?articleId=14347 (posećeno 1. 10. 2011).

http://www.nuns.rs/vesti/view.jsp?articleId=14374 (posećeno 1. 10. 2011).

http:/www.blic.rs/Zabava/Vesti/236494/RRA-blago-kaznila-Pink-naDvoru-nastavili--sa-sukobima (posećeno 1. 10. 2011). 


\title{
DEJAN PRALICA
}

Dejan Pralica

University of Novi Sad, Faculty of Philosophy, Novi Sad

\section{AUDIENCE AND INDEPENDENT REGULATORY AGENCY'S ATTITUDES TOWARDS REALITY PROGRAMS IN SERBIA: A CASE STUDY OF DVOR (PALACE)}

\begin{abstract}
According to the official research data of the AGB Nielsen (April, 2010) people in Serbia spend more time watching TV than any other nation in the world. Reality shows are among the most popular programs on televisions with national frequency. While most of these programs are franchises, RTV Pink, the most popular commercial television in Serbia, offered the audience in the region a reality show of its own called Dvor (The Palace). Although the reality programs have been broadcasted in Serbia since 2005 (Veliki brat, Operacija trijumf, Survivor, Farma, Parovi, 48 sati svadba, Menjam ženu, Ja imam talenat, Radna akcija, Domaćine, oženi se, Paklena kuhinja, Vreme je za bebe, Maldivi), the controversial reactions of the public and media regulatory bodies culminated during the broadcasting of Dvor. The aim of this paper is to find out why physical violence and explicite hate speach in Dvor provoked more reactions of the audience (approval and disapproval alike), print media (detailed daily reports of what happened in the program) and media experts and independent regulatory bodies than similar incidents in other reality shows.The general hypothesis is that Dvor was so popular because of its share in Pink's program (more than 10 hours a day), as well as the fact that daily newspapers and magazines gave detailed reports of the events and participants of the show. The first particular hypothesis is that Dvor attracted great interest in the audience, but also in the media, simply because celebrities were the participants of the show. The second particular hypothesis is that the reactions and conclusions of the independant regulatory body Republic Broadcasting Agency - after the incidents in this program, did not meet the expectations of media experts. The corpus of the study contains the selected fragments from the first (Ulazak) and last (Finale) episodes of the program, the situations in which physical violence and hate speech appeared, as well as the reactions of media experts in daily newspapers and magazines and the audience's comments on the Internet forums and social networks.
\end{abstract}

Keywords:Realityshow,,,Dvor",share, hatespeech,public, independent regulatory body 